\title{
Social Media Content Headlines and Their Impact on Attracting Attention
}

\author{
Kishokanth Jeganathan \\ Department of Commerce and Marketing, Poznań University of Economics and Business, Poland \\ kishokanth.jeganathan@ue.poznan.pl \\ Andrzej Szymkowiak \\ Department of Commerce and Marketing, Poznań University of Economics and Business, Poland ${ }^{1}$ \\ andrzej.szymkowiak@ue.poznan.pl
}

Received: 04 February 2020/ Revised: 23 June 2020/ Accepted: 30 June 2020/ Published online: 13 November 2020

\begin{abstract}
Social media is an important source of product information for many users. Marketing in social media is based not only on building a community around the brand, but social media is used as a way to reach a defined group of users with a marketing message. These users are shown content, including promoted posts, which is to draw their attention, interest and get them to action, i.e. click on the link and read the article promoting an event or product. In this article, we investigated how the different headline wordings (question, traditional, forward referring) affect the desire to read the article. An experiment was conducted on 75 participants, which confirmed that the header has a large effect size. The ANOVA analysis was carried out in two stages, additionally taking into account the importance and general interest in the subject of the article by users. Finally, the possible business implications, limitations, and directions for future research were identified.
\end{abstract}

JEL classification: D71, A14, D91, L82

Keywords: social media promotion, headlines, forward referencing, urge to read, content marketing

\section{INTRODUCTION}

With the global digital population hitting the 4.5 billion mark in 2020, with 3.81 of it being social media users (Clement, 2020), the internet is undoubtedly the most powerful medium of advertising today, with traditional marketing mediums such as newspapers and radio being on a rapid decline, as cited by Horbal, Naychuk-Khrushch, and Orlykova (2017) and Confos and Davis (2016). The reason for this shift is given by Talafuse and Brizek (2014), who present demassification, interactivity, and synchronicity as the hallmarks of new media. Adding to the same are Arvidsson and Caliandro (2015) and Hennig-Thurau et al. (2010), who claim that digital communication allows brands to replace mass communication with micro targeted ads that are

\footnotetext{
Andrzej Szymkowiak, Poznań University of Economics and Business, al. Niepodległości 10, 61-875, Poznań.
} 
more personal and have been discovered to be able to alter customer relationships, behaviors and interactions. This microtargeting, when combined with technologies that allow retargeting, where brands use an individual's search history to display suitable ads (Douglas \& Pracejus, 2020), can be a powerful tool for digital marketers who are able to use the data generated to optimize their ads further. This constant barrage of advertisements, however, has decreased the public attention to digital ads, causing the development of a phenomenon known as content blindness (Severson, 2016) which is similar to banner blindness where users habitually ignore any advertising banners they see while surfing the internet (Müller et al., 2009). Text ads are not immune to the same as per Owens, Chaparro, and Palmer (2011), who present text blindness as a similar issue where recipients ignore ads written as text. To worsen matters, over $47 \%$ of the internet users worldwide appear to have installed ad blockers to prevent the display of any ads (Ahmad, 2019). With this mounting distaste for ads, marketers are now faced with a challenge to pull customers towards their brands instead of pushing the brands to them.

One solution to the aforementioned issue is producing content that is less oriented towards overt selling and more towards helping satisfy user needs and wants. This is where content marketing whose sole purpose is to connect and build relationships with customers can prove useful (Vinerean, 2017). Such content marketing efforts distributed across the internet, however, must cause an urge to read and it is where headlines can be profoundly useful (Yimin, Niall, $\&$ Victoria, 2015). Content writers know this and have been using headlines of various stylistic features in order to create the urge to read the full story (Kuiken, Schuth, Spitters, \& Marx, 2017). Literature on headlines of content marketing material and their impact on the urge to read, however, appears to be scarce as most of the research has been conducted in a newspaper context with a focus on metrics such as clicks, attention and popularity. The research question that we will endeavor to answer in this work, therefore, is whether the type of content marketing headline can have an impact on the urge to read the content itself.

To achieve the above, this paper will first review secondary research on content marketing and how it can be a boon to a company's integrated marketing strategy and indicate the importance of headlines in drawing customers to content. The secondary literature review will then end with a discussion of three stylistic manners in which headlines can be produced and their impact on metrics related to the urge to read such as clicks, attention and popularity. The above will be followed by an introduction to the methods this research will adhere to and a review of the findings. The authors will then discuss the findings together with their theoretical and practical implications for marketers. The paper will end with an analysis of its limitations and aims for further research.

\section{LITERATURE REVIEW}

\subsection{Pulling Customer With Content Marketing}

Holliman and Rowley (2014) define content marketing as "creating, distributing and sharing relevant, compelling and timely content to engage customers at the appropriate point in their buying consideration processes, such that it encourages them to convert to a business building outcome". Adding to this are Halligan and Shah (2010), who cite content marketing as an inbound marketing strategy for customers who have already done their research on a product and can benefit from valuable content to add to their decision making. On a different line of thinking are Rose and Pulizzi (2011), who argue that content marketing is one where the customers are provided with a valuable experience. Doing so appears to be of growing importance as customers of the modern age are now expecting more investment from brands into the relationship with them before there can be a scenario in which a purchasing decision is made (Odden, 2012). Such marketing is the 
only viable option as one attempts to pull customers to the product and not push the product to the customer (Jefferson \& Tanton, 2013), helping companies to position their products and even reinforce them (Gagnon, 2014). Affirming this is Zahay (2014), who states that content marketing is the way forward in a digital environment where ads are considered disruptive by consumers. Such content marketing is aimed at building long-term relationships with clients (Holliman \& Rowley, 2014) and helps a brand to communicate with potential customers without selling products directly through advertising whose efforts are aimed at increasing sales in the short run. This communication created with the customers in turn boosts the brand perception in the minds of its consumers, creating more engagement and trust, driving sales for the long run (Hollebeek \& Macky, 2019). Reaffirming the same are Vinerean (2017) and Liu and Huang (2015), who present content marketing as an excellent means of connecting and building relationships with customers due to its unobtrusive nature. Produced below in Table 1 is a list of the most common content marketing formats through which organizations strive to create value to their customers.

Table 1

Common content marketing formats

\begin{tabular}{ll}
\multicolumn{1}{c}{ Format } & \multicolumn{1}{c}{ Description } \\
Blog posts & $\begin{array}{l}\text { Posted on a regular basis on a blog and shared widely on social media to attract new } \\
\text { and recurring visits. }\end{array}$ \\
\hline eBooks & $\begin{array}{l}\text { Lead generation tools, acting as a resource of information on a certain subject for potential } \\
\text { consumers. This provides credibility to the organization and creates trust in the eyes } \\
\text { of the customer. }\end{array}$ \\
\hline Infographics & $\begin{array}{l}\text { Used for its ability to bring meaning to complex data in an easy way to understand visual } \\
\text { format. }\end{array}$ \\
\hline Videos & $\begin{array}{l}\text { A very engaging medium of communication used to touch on products, services and topics } \\
\text { of interest to consumers. }\end{array}$ \\
\hline Podcasts & $\begin{array}{l}\text { Pre-recorded interviews or audio materials that are shared with an audience to build trust } \\
\text { in an expert on certain matters. }\end{array}$
\end{tabular}

Note. Reprinted from Target Your Customers With These Top 10 High-Performing Types of Content Marketing, by Sherman, retrieved from https://www.lyfemarketing.com/blog/types-of-content-marketing/ Copyright 2019 by https://wwlyfemarketing.com

Content created for the purpose of content marketing, when shared on the internet, joins the multitude of content that is displayed to the intended recipients. Content marketers must therefore do more than produce the content and discover means of increasing the urge to read by users so that they will end up perusing the main content. One of the key means by which this can be accomplished is via the use of good headlines.

\subsection{The State of Headlines Today}

The role of headlines is one that has been studied extensively across both print and online news media. Early research on the functions of headlines tasked them with giving the readers who might be scanning a newspaper a clear idea of what the article was about (Van Dijk, 1988). Bell (1991) on the other hand believes that headlines are tasked with drawing the attention of readers and provoking them into reading the full article. Adding to the same are Mahmood, Javed, and Mahmood (2011), who mention that headlines act as a precursor to the main article. Dor (2003) offers a different opinion as headlines are not only tasked with summarizing, but also building a sense of affinity and relevance to the reader. Such headlines, according to him, must find the balance between being short and clear, whilst providing the reader with a rich summary of the content that one can expect in the article the headline is referring to. Adding to this are Iarovici and Amel (1989), who discuss headlines that can in fact help the reader understand the 
meaning of the content that is being referred to. Offering a more holistic input into the functions of headlines is Conboy (2013), who divides them into 3. The first two, he argues, are to offer those who might be reading a short summary of the news and grab their attention. The third is to offer an initial indicator of the style and news values of the newspaper in question so that the reader can make a decision.

The increase of online content consumption, however, has shifted the role of a headline into one that is more focused on getting the reader's attention. Reiterating this are Jiang, Guo, Xu, Zhao, and $\mathrm{Fu}$ (2019), who state that the online media yearning for the highest website visits has changed the function of the headline to one that is more attention grabbing than informing. This is all the more important as there is an increasing number of news consumers who do so via social media networks (Mitchell \& Page, 2015), which in turn show the popular content to more users via their algorithms. This increasing demand for user clicks has given rise to a significant amount of competition for attention, prompting news producers to keep vying for the urge to read from their audience. All the more so since good headlines can be linked to the popularity of content (Piotrkowicz, Dimitrova, Otterbacher, \& Markert, 2017). Affirming the same are Blom and Hansen (2015), who claim that those involved in the formulation of headlines are occupied with one question, namely 'what makes readers click?', a question which García-Orosa, Santorum, and García (2018) put forward to prompt those who create headlines to take into careful consideration their word choices as they play a decisive role in the content ranking.

This competition, as argued by Kuiken et al. (2017), has given rise to an increasing amount of clickbait, a phenomenon in which content producers write vague headlines in order to induce curiosity and draw readers to clicking on the headline. Such clickbait headlines have been investigated by many such as Blom and Hansen (2015) and Pengnate (2016) for their provoking content and their ability to revolve around the notion of the unknown, tapping into a lack of knowledge with a promise of gratification upon acting on the desired action (Potthast, Köpsel, Stein, \& Hagen, 2016). This arousal of curiosity and the inherent need to satisfy it can be best explained by Loewenstein (1994), who cites the phenomenon known as a knowledge gap. The knowledge gap, he asserts, is realized when one's attention is drawn to a gap in knowledge, driving the said individual to obtain the missing information or eliminate the feeling of deprivation. Such headlines, as argued by Mormol (2019), who conducted recent research on the dominant role clickbait plays in contemporary online headlines, utilize certain idiosyncratic mannerisms or techniques that are immediately associated with them, and forward references are one of the most prominent. The main reason behind the success of forward referencing headlines can be alluded to their ability to arouse the curiosity of those who come across them (Potthast, Köpsel, Stein, \& Hagen, 2016). Another stylistic feature that is often used in clickbait, according to Mormol (2019), is the use interrogative forms (questions) as observed in the research of Kuiken et al. (2017), Scacco and Muddiman (2016) and Lai and Farbrot (2013).

\subsubsection{Forward referencing headlines}

Forward referencing, Blom and Hansen (2015) believe, is 'the act of alluding to aspects that will occur further on in a story at an earlier point, often leaving things unexplained, vague or avoiding directly referring to a key feature of the story'. Such forward referencing headlines, as claimed by Kuiken et al. (2017), contain signal words such as why, this, what or pronouns such as he or she in order to arouse the curiosity of readers. Adding to this is Hess (2016), who cites the use of pronouns, adverbs, imperatives, interrogatives, or general nouns that coerce an individual to read the article as identifiers of headlines that are forward referencing. Adding to the identifiable features of such headlines are Blom and Hansen (2015), who assert that forward referencing headlines occur in two forms - discourse deixis and cataphora. Discourse deixis, they claim, is "reference to forthcoming (parts of the) discourse relative to the current location in the discourse, e.g. This is the best news story you will ever read". Cataphora is rather similar and 
refers to a word or a phrase that is found later in the text, e.g. when he arrived at the crime scene, the journalist interviews the victim's wife.

The effectiveness of forward referencing headlines in content marketing, however, cannot be shrugged off as an A/B test that tested the clicks on a call to action (CTA) button discovered a $927 \%$ increase on the content that aroused one's curiosity (Wiebe, 2014). The same was found to be true in the research of Kelly (2016), who discovered that forward referencing headlines that alluded to content at later points in the article had increased click through rates. These findings match those of Kuiken et al. (2017), who conducted research on the textual and stylistic features of new headlines and on their performance and discovered those with personal or possessive pronouns to have a significant positive impact. Adding to this are the findings of Biyani, Tsioutsiouliklis, and Blackmer (2016), who discovered content that was more informal and had forward referencing features to perform better than the content that was non-clickbait (traditional). Offering a completely new direction of thinking are the findings of Ifantidou (2009), who discovered norms such as length, clarity, and information to be of no importance to the selection of headlines as the readers were found to attach more value to headlines that were underinformative, creative, yet autonomous texts. In lieu of these findings one can consider the primary task of headlines to grab attention as Bell (1991) posited and not a summary as Van Dijk (1988) cites. Adding to this are the findings of Blom and Hansen (2015), who in their analysis of 2013-2014 online Danish publications discovered that forward referencing was used 17\% of times. This popularity of forward referencing headlines, however, appears to have diminished later on as Kilgo and Sinta (2016) discovered forward referencing to be present in only $7.3 \%$ of viral media.

\subsubsection{Headlines posed as questions}

Headlines posed as questions are not a new phenomenon as they have been used in print marketing (Howard, 1988) to arouse curiosity in all those who come across them. Such headlines with interrogatory elements have made their way into computer-mediated communication such as online advertising and online news media and come in many forms such as hypothetical questions, rhetorical questions, leading questions, tag questions and are usually accompanied by selfreferencing cues that are interned to make the reader relate to the message more (Lai \& Farbrot, 2013). Such self-referencing cues increase the persuasive effects advertising has on individuals (Debevec \& Iyer, 2006) and garner the attention of readers (Howard, 1988) by creating a sense of uncertainty that can only be resolved via a click to see the content (Scacco \& Muddiman, 2019). Such headlines, as argued by Blom and Hansen (2015), are akin to cliff-hangers, taunting all those who come across them in order to get them to read the content in question. This tapping into the curiosity that is inherent in humans is what drives the clicks on headlines posed as questions (Lockwood, 2016) and can prove to be a useful strategy if the content at the end of the click is in fact useful and answers the question.

There is a dearth of research on how question-type headlines impact readership, as claimed by Lai and Farbrot (2013). Research prior to the internet era, however, discovered that such headlines can be used to rouse interest (Soley \& Reid, 1983). Such headlines, according to Myers and Haug (1967), can generate more attention when the majority of headlines are in the question form, despite having no effect on recall when compared with those that were declarative (traditional headlines). This, however, appears to have changed in recent times as the findings of Scacco and Muddiman (2016) discovered question-based headlines to be considered in a negative outlook and had lower engagement rates against those considered traditional. In a similar line of thinking are Kuiken et al. (2017), who state that it is not the presence but the absence of questions in headlines that increases performance. This debate on the performance of headlines framed as questions is not one that appears to be helpful as we discovered in the findings of Lai and Farbrot (2013), who proved such headlines to be better for clicks than the traditional headlines. 


\subsubsection{Traditional news headlines}

Known as summary headlines, the core function of a headline that follows traditional publishing standards is to provide a summary of an inverted pyramid-structure news story (Andrew, 2016) in a concise, clear and relatively certain tone. Such headlines provide the readers with summary points of the main story and informational clarity unlike those that are of forward referencing or questioning forms. They also allow those who seek information to find it, unlike those that arouse curiosity and lead to doubt the quality of the information readers may find upon selection (Kilgo \& Sinta, 2016). According to those authors, traditional headlines typically identify the "who" or "what" that is central to the news story. Adding to this, Chakraborty, Paranjape, Kakarla, and Ganguly (2016) argue that traditional headlines typically contain mostly content words referring to specific persons and locations, while the function words are left out for readers to interpret from context. Adding to this list of identifiers of traditional news headlines, the same authors claim that they contain very few instances of word shortenings when compared to headlines that were more of a clickbait nature.

As for how traditional headlines perform, Gessler (2017) states that they are twice as effective for click-through rates when compared with those that are more obscure. Adding to this are the findings of Scacco and Muddiman (2016), who found respondents to react more positively towards traditional headlines when compared with those that were framed as questions. The very same study also found engagement with traditional headlines to be more pronounced than that with headlines framed as questions. Similar are the findings of Breaux (2015), who found clear headlines to score higher click-through rates than those that were short (as observed in the forward referencing and question headlines). The findings of Biyani et al. (2016), who created a model for detecting clickbait, however, suggest that headlines that were informal and of a forward referencing nature performed better than those that were traditional. Adding to this research on traditional headlines and their impact on performance is Ifantidou (2009), who discovered that norms such as length, clarity, and informativeness (as expected of traditional headlines) played no part in reader selection as the respondents opted for texts that were underinformative, creative, yet autonomous. Research from Lai and Farbrot (2013), who investigated the effect question headlines have on clicks, discovered that integrative questions were much better for readership than those that were declarative (traditional).

Having reviewed the secondary literature on how the three stylistic manners in which headlines can be produced can impact the urge to read related metrics such as clicks, attention and popularity, we hypothesize that the style of an individual headline does in fact have a corresponding effect on its ability to cause an urge to read.

\section{METHODS}

The sample for this research was recruited via social media using the convenient sampling method, covering persons from the authors' social media contact network. Before the actual test held at the university premises, a trial test was conducted on 3 individuals to identify potential ambiguities in the instructions, any typos or smoothness of the survey. After pre-testing, there were a total of 75 respondents out of whom $44(58 \%)$ were female and $31(42 \%)$ were male of an average age of $25.8(\mathrm{SD}=4.78)$. The majority of participants were bachelor $(61 \%)$ and master's degree $(28 \%)$ holders. These respondents were then divided into three equal groups (25 each), and exposed to the versions of one title: traditional - Commons leader quits government; forward referencing - Here's why the Commons leader just quit the government; question - Did the Commons leader just quit the government? After reading the title, participants were exposed to 
questions, at which point they were relying on their recall of the headlines instead of a conscious analysis of stimulants. The dependent variable 'urge to read' was assigned a marker and measured in line with the research of Scacco and Muddiman (2019), who conducted similar research on news headlines and anticipated news engagement (Very Unlikely (1) to Very Likely (5) that individuals would read the article). To validate our findings to a greater degree, the participants were tested on their urge to read via three questions (Seeing such a title, I would have an inclination to read the article; Seeing such a title, I would have the desire to read the article; Seeing such a title, I would feel an urge to read the article). Cronbach's alpha for the variable was .93 and average variance extracted was 0.82, which exceeds the required values (MacKenzie, Podsakoff, \& Podsakoff, 2011). In addition, participants were asked about their general interest in the subject (The subject of this article is important to me) on a scale of 1-definitely not to 7-definitely yes $(\mathrm{M}=3.47$, $\mathrm{SD}=1.96)$

\section{RESULTS}

A statistical analysis was performed based on the collected empirical material. An analysis of variance (ANOVA) was conducted to determine whether there were significant differences in the urge to read an article by type of headline. Prior to the analysis, ANOVA assumptions were examined - the assumptions of univariate normality of residuals and homogeneity of variance. Normality was evaluated using a Q-Q scatterplot. Levene's test indicated equal variances $(\mathrm{F}=1.023, \mathrm{p}=.365)$. The results of the ANOVA were significant, $\mathrm{F}(2,72)=5.381, \mathrm{p}=.007$, $\eta 2=0.130$, indicating that there were significant differences in the urge to read among the types of headline (Table 1). The means and standard deviations are presented in Table 2.

Table 1

Analysis of Variance Table for Anxiety by Weight and Depressed

\begin{tabular}{|l|c|c|c|c|c|c|}
\hline \multicolumn{1}{c|}{ Cases } & Sum of Squares & df & Mean Square & F & p & $\boldsymbol{\eta}^{2}$ \\
\hline Type of headline & 28.011 & 2.000 & 14.005 & 5.381 & 0.007 & 0.130 \\
\hline Residual & 187.403 & 72.000 & 2.603 & & &
\end{tabular}

Note. Type III Sum of Squares.

Figure 1

Means of urge to read by types of headline

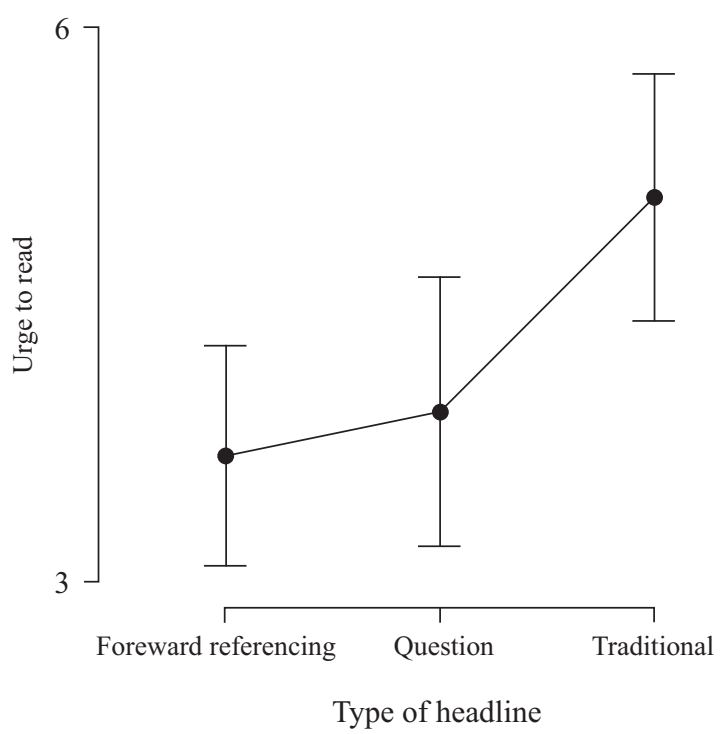

Note. Error bar - Confidence interval (95\%). 
Paired $t$-tests were calculated between each type of measurements to further examine the differences of headlines. Tukey pairwise comparisons were conducted for all significant effects. The mean of forward referencing $(M=3.681, S D=1.445)$ was significantly smaller than for traditional $(M=5.080, S D=1.614), p=.008$. The mean of traditional type was significantly higher than for question $(M=3.920, S D=1.765), p=.035$. No other significant effects were found (Table 2).

Table 2

Post-hoc comparisons - Type of headline

\begin{tabular}{|c|c|c|c|c|c|c|}
\hline & & Mean Difference & SE & $t$ & Cohen's d & $p_{\text {tukey }}$ \\
\hline \multirow[t]{2}{*}{ Forward referencing } & Question & -0.239 & 0.456 & -0.523 & -0.148 & 0.860 \\
\hline & Traditional & -1.399 & 0.456 & -3.066 & -0.914 & 0.008 \\
\hline Question & Traditional & -1.160 & 0.456 & -2.543 & -0.686 & 0.035 \\
\hline
\end{tabular}

Conducting weighted least squares using Category Interest as a weight, previous results were confirmed $\mathrm{F}(2.72)=6.873, \mathrm{p}=0.002$, and the effect size improved $(\eta 2=.160)$. Considering this factor, the post-hoc analysis stage did not reveal new effects.

\section{DISCUSSION}

Our findings confirm that the manner in which a headline is formulated has an impact on the urge to read the corresponding article. This is an affirmation of the findings by Piotrkowicz et al. (2017), who found a link between good headlines and their popularity. The most important finding to us was that it was headlines written in the traditional sense (concise, clear and in a relatively certain tone) that caused the highest urge to read among the respondents. This mirrors the findings of Scacco and Muddiman (2019), who found their respondents to react more positively and engage with traditional headlines when compared with those with questions. The findings of Gessler (2017) were also replicated in this research as the traditional headlines were favored over more obscure forward referencing and question-based headlines.

Having analyzed the findings, it is clear that headlines that do not provide a summary of the content in a clear and concise manner can reduce the urge to read. This matches the findings of Breaux (2015), who discovered that headlines that were shorter (as with forward referencing and question headlines) see reduced click-through rates when compared to the traditional ones. What was interesting, however, was that there was no difference between the question and forward referencing, despite very different stylistic features embedded within them. This contrasts with the findings of Lai and Farbrot (2013), who discovered headlines with questions to outperform the traditional ones, and those of Wiebe (2014) and Kelly (2016), who discovered forward referencing to be a great tactic for increasing click-through rates. The reason for this respondent behavior, we feel, is the frustration associated with encountering headlines that are obscure in nature. Such headlines are associated with clickbait and are now looked down by internet-savvy individuals who are very well aware of the low-quality content presented by articles with such headlines. This indicates that content writers must now ensure that they provide precise information, without resorting to taunts and concealing information.

The discoveries we made within this article have some significant practical implications for organizations that engage in content marketing. It is clear that the internet users of today have a short attention span, access to many online channels which inundate them with information, requiring organizations to be upfront about the content they are publishing in attempts to pull the customer towards them. Such content marketing efforts should focus on value provision without 
resorting to trickery and do it concisely to carve a trusted voice for the article content as such in the very crowded internet marketplace we see today.

\section{CONCLUSION}

This research set out to observe whether the type of headlines impacted the urge to read content and discovered that traditional headlines with clear, concise language outperformed those that were forward referencing and of a question form. An interesting fact that we must highlight is that the respondents did not display any special preference as to either forward referencing headlines or those framed as questions. These findings provide us with a clear idea on how internet-savvy users are now more partial towards headlines that are clear and can be trusted to provide them with value and not those that are obscure. Those engaged in content marketing efforts should therefore take note of such consumer insights and update their marketing strategies accordingly.

We must mention that the headline base used for this research is of socio-political nature and might have influenced the responses obtained from the respondents. We aimed to expand this to other thematic content in order to test the validity of our current findings. Another limitation we would like to highlight is the sample size used for this research, despite it being characteristic of experimental studies during which the variable number is limited and under controlled conditions. The decision to embark on the research with 75 respondents was justified as the statistically significant results obtained correspond to the variable size effect, making any increments to the sample economically unjustified with no significant impact on the cognitive value of the study results. An interesting topic of research to build on the current research with a bigger sample number is to investigate how the type of headline can impact the credibility and perceived usefulness of content. The findings gained therein could then be used as a foundation for investigating how the perceived familiarity and credibility of a publisher could impact the urge to read.

\section{References}

Ahmad, I. (2019). Global ad blocking behavior 2019 [Infographic]. Retrieved from https://www.socialmediatoday. com/news/global-ad-blocking-behavior-2019-infographic/551716/

Andrew, B.C. (2016). Media-generated shortcuts: Do newspaper headlines present another roadblock for low-information rationality?. Harvard International Journal of Press/Politics, 12(2), $24-43$. doi:10.1177/1081180x07299795

Arvidsson, A., \& Caliandro, A. (2015). Brand public. Journal of Consumer Research, 42(5), 727-748. doi:10.1093/ jer/ucv053

Bell, A. (1991). The language of news media. Oxford: Blackwell.

Biyani, P., Tsioutsiouliklis, K., \& Blackmer, J. (2016). 8 amazing secrets for getting more clicks: Detecting clickbaits in news streams using article informality.

Blom, J.N., \& Hansen, K.R. (2015). Click bait: Forward-reference as lure in online news headlines. Journal of Pragmatics, 76, 87-100. doi:https://doi.org/10.1016/j.pragma.2014.11.010

Breaux, C. (2015). You'll never guess how chartbeat's data scientists came up with the single greatest headline. Retrieved from https://blog.chartbeat.com/2015/11/20/youll-never-guess-how-chartbeats-data-scientistscame-up-with-the-single-greatest-headline/

Chakraborty, A., Paranjape, B., Kakarla, S., \& Ganguly, N. (2016). Stop clickbait: Detecting and preventing clickbaits in online news media.

Clement, J. (2020). Worldwide digital population as of April 2020. Retrieved from https://www.statista.com/ statistics/617136/digital-population-worldwide/

Conboy, M. (2013). The language of the news. Englang, UK: Routledge.

Confos, N., \& Davis, T. (2016). Young consumer-brand relationship building potential using digital marketing. European Journal of Marketing, 50(11), 1993-2017. doi:10.1108/EJM-07-2015-0430 
Debevec, K., \& Iyer, E. (2006). Self-referencing as a mediator of the effectiveness of sex-role portrayals in advertising. Psychology and Marketing, 5, 71-84. doi:10.1002/mar.4220050106

Dor, D. (2003). On newspaper headlines as relevance optimizers. Journal of Pragmatics, 35(5), 695-721. doi:10.1016/ s0378-2166(02)00134-0

Douglas, O.G., \& Pracejus, J.W. (2020). Customized advertising: Allowing consumers to directly tailor messages leads to better outcomes for the brand. Journal of Business Research, 116, 245-257. doi:10.1016/j. jbusres.2020.04.054

Gagnon, E. (2014). Goodbye, B2B brand marketing: Developing content-based marketing programs for the postmarketing era. International Management Review, 10, 68-71.

García-Orosa, B., Santorum, S., \& García, X. (2018). Use of clickbait in the online news media of the 28 EU member countries. Revista Latina de Comunicacion Social.

Gessler, K. (2017). 13 more before-and-after examples of headline magic. Retrieved from http://mediashift. org/2017/04/13-examples-headline-magic/

Halligan, B., \& Shah, D. (2010). Inbound marketing: Get found using Google, social media, and blogs. Hoboken, NJ: Wiley \& Sons.

Hennig-Thurau, T., Malthouse, E.C., Friege, C., Gensler, S., Lobschat, L., Rangaswamy, A., \& Skiera, B. (2010). The impact of new media on customer relationships. Journal of Service Research, 13(3), 311-330. doi:10.1177/1094670510375460

Hess, B. (2016). You'll never believe how misleading this title is. Retrieved from http://brianleehess.com/essays/ youll-never-believe-how-misleading-this-title-is

Hollebeek, L., \& Macky, K. (2019). Digital content marketing's role in fostering consumer engagement, trust, and value: Framework, fundamental propositions, and implications. Journal of Interactive Marketing, 45, $27-41$. doi:10.1016/j.intmar.2018.07.003

Holliman, G., \& Rowley, J. (2014). Business to business digital content marketing: Marketers' perceptions of best practice. Journal of Research in Interactive Marketing, 8(4), 269-293. doi:10.1108/JRIM-02-2014-0013

Horbal, N., Naychuk-Khrushch, M.B., \& Orlykova, B. (2017). Internet advertising: The specifics, tendencies of development and impact on sales. ECONTECHMOD: An International Quarterly Journal on Economics of Technology and Modelling Processes, 6(1), 37-46.

Howard, D.J. (1988). The prevalence of question use and question strategies in print advertising. Current Issues and Research in Advertising, 11(1-2), 89-112. doi:10.1080/01633392.1988.10504930

Iarovici, E., \& Amel, R. (1989). The strategy of the headline. Semiotica, 77(4), 441. doi:https://doi.org/10.1515/ semi.1989.77.4.441

Ifantidou, E. (2009). Newspaper headlines and relevance: Ad hoc concepts in ad hoc contexts. Journal of Pragmatics, 41(4), 699-720. doi:https://doi.org/10.1016/j.pragma.2008.10.016

Jefferson, S., \& Tanton, S. (2013). Valuable content marketing. London: KoganPage.

Jiang, T., Guo, Q., Xu, Y., Zhao, Y., \& Fu, S. (2019). What prompts users to click on news headlines? A clickstream data analysis of the effects of news recency and popularity. Paper presented at the Information in Contemporary Society, Cham.

Kelly, L. (2016). Clickbait: These studies show PR how to perfect the headline. Retrieved from http://prmeasured. com/clickbait-studies-pr-perfect-headline/

Kilgo, D.K., \& Sinta, V. (2016). Six things you didn't know about headline writing: Sensationalistic form in viral news content from traditional and digitally native news organizations. Retrieved from https://isojjournal. wordpress.com/2016/04/14/six-things-you-didnt-know-about-headline-writing-sensational-form-in-viralnews-of-traditional-and-digitally-native-news-organizations/

Kuiken, J., Schuth, A., Spitters, M., \& Marx, M. (2017). Effective headlines of newspaper articles in a digital environment. Digital Journalism, 5(10), 1300-1314. doi:10.1080/21670811.2017.1279978

Lai, L., \& Farbrot, A. (2013). What makes you click? The effect of question headlines on readership in computermediated communication. Social Influence, 9, 289-299. doi:10.1080/15534510.2013.847859

Liu H.W., \& Huang H.C. (2015). Tradeoff between push and pull strategy: The moderating role of brand awareness. In H. Spotts (Ed.), Marketing, technology and customer commitment in the new economy. Developments in marketing science: Proceedings of the academy of marketing science (pp. 259-264). Cham: Springer. https:// doi.org/10.1007/978-3-319-11779-9 98

Lockwood, G. (2016). Academic clickbait: Articles with positively-framed titles, interesting phrasing, and no wordplay get more attention online. The Winnower. doi:10.15200/winn.146723.36330

Loewenstein, G. (1994). The psychology of curiosity: A review and reinterpretation. Psychological Bulletin, 116, 75-98. doi:10.1037/0033-2909.116.1.75

Mahmood, M.A., Javed, S., \& Mahmood, R. (2011). A critical discourse analysis of the news headlines of budget of Pakistan FY 2011-2012. Interdisciplinary Journal of Contemporary Research in Business, 3. Retrieved from https://journal-archieves8.webs.com/120-129.pdf 
Mitchell, A., \& Page, D. (2015). State of the news media 2015. Retrieved from https://assets.pewresearch.org/wpcontent/uploads/sites/13/2017/05/30142603/state-of-the-news-media-report-2015-final.pdf

Mormol, P. (2019). 'I urge you to see this...'. Clickbait as one of the dominant features of contemporary online headlines. Social Communication, 5(2), 1-10. doi:https://doi.org/10.2478/sc-2019-0004

Müller, J., Wilmsmann, D., Exeler, J., Buzeck, M., Schmidt, A., Jay, T., \& Krüger, A. (2009). Display blindness: The effect of expectations on attention towards digital signage. Berlin, Heidelberg.

Myers, J., \& Haug, A. (1967). Declarative vs. interrogative advertisement headlines. Journal of Advertising Research, $7(3)$.

Odden, L. (2012). Optimize. Hoboken, NJ.: Wiley.

Owens, J.W., Chaparro, B.S., \& Palmer, E.M. (2011). Text advertising blindness: The new banner blindness?. J. Usability Studies, 6(3), 172-197.

Pengnate, S.F. (2016). Measuring emotional arousal in clickbait: Eye-tracking approach. Paper presented at the Twenty-second Americas Conference on Information Systems, San Diego. Retrieved from https://pdfs. semanticscholar.org/d0f1/9dae77082725239a3be0254e67004769bc4b.pdf

Piotrkowicz, A., Dimitrova, V., Otterbacher, J., \& Markert, K. (2017). Headlines matter: Using headlines to predict the popularity of news articles on Twitter and Facebook.

Potthast, M., Köpsel, S., Stein, B., \& Hagen, M. (2016). Clickbait detection (Vol. 9626).

Rose, R., \& Pulizzi, J. (2011). Managing content marketing. Cleveland, OH: CMI Books.

Scacco, \& Muddiman. (2016). Investigating the influence of "clickbait" news headlines. Retrieved from https:// mediaengagement.org/research/clickbait-headlines/

Scacco, \& Muddiman, A. (2019). The curiosity effect: Information seeking in the contemporary news environment. New Media \& Society, 146144481986340. doi:10.1177/1461444819863408

Severson, S. (2016). Is 'content blindness' the new 'banner blindness'?. Retrieved from https://www.forbes.com/ sites/forbesagencycouncil/2016/08/23/is-content-blindness-the-new-banner-blindness/\#693c33774f84

Soley, L.C., \& Reid, L.N. (1983). Industrial ad readership as a function of headline type. Journal of Advertising, 12(1), 34-38. doi:10.1080/00913367.1983.10672828

Talafuse, A., \& Brizek, M.G. (2014). Traditional and digital media advertising preference: A descriptive evaluation of Billings, Montana mothers.

Van Dijk, T.A. (1988). News as discourse. Hillsdale: Lawrence Erlbaum Associates.

Vinerean, S. (2017). Content marketing strategy. Definition, objectives and tactics. Expert Journal of Marketing, $5(2), 92-98$.

Wiebe, J. (2014). Should you use a curiosity gap to persuade your visitors to click?. Retrieved from https:// copyhackers.com/2014/04/curiosity-gap/

Yimin, C., Niall, J.C., \& Victoria, L.R. (2015). Misleading online content: Recognizing clickbait as "false news". Paper presented at the Proceedings of the 2015 ACM on Workshop on Multimodal Deception Detection, Seattle, Washington, USA. https://doi.org/10.1145/2823465.2823467

Zahay, D. (2014). Beyond interactive marketing. Journal of Research in Interactive Marketing, 8(4). doi:10.1108/ JRIM-08-2014-0047 